\title{
La novela de la Revolución Mexicana y el cancionero popular: confluencias
}

Ana Marco González ${ }^{1}$

Resumen. El presente artículo examina las relaciones que se establecen entre la novela de la Revolución Mexicana de las décadas del veinte al cuarenta y el cancionero popular. En su primera parte, atiende a las semejanzas que se dan entre esta narrativa y la balada conocida como corrido, para analizar a continuación la funcionalidad de la cita de testimonios del cancionero por el texto escrito.

Palabras clave: novela de la Revolución Mexicana; cancionero popular; corrido; folclore; intertextualidad.

[en] The novel of the Mexican Revolution and the popular songbook: confluences

Abstract. This article examines the relationships between the novel of the Mexican Revolution from the twenties to the fourties and popular music. Firstly, it reviews the correspondences between these narratives and the ballad form known as corrido. It analyzes then the presence of pieces of the Mexican folk tradition in the written text.

Keywords: novel of the Mexican Revolution; popular music; corrido; folklore; intertextuality.

Sumario. 1. Introducción. 2. El corrido y la novela de la Revolución: confluencias. 3. La apropiación novelística del cancionero. 4. Conclusiones.

Cómo citar: Marco González, A. (2019) La novela de la Revolución Mexicana y el cancionero popular: confluencias, en Anales de Literatura Hispanoamericana 47, 265-284.

\section{Introducción}

El corrido mexicano... influye en la literatura docta. ... Existen ya entre nosotros individuos que lo toman como un modelo de forma capaz de entregar obras literarias empapadas en sabor popular, pero resueltas con técnica.

Vicente T. Mendoza

Entre las numerosas consecuencias del alzamiento maderista de 1910 se encuentra como es sabido el desarrollo del corpus novelístico de la Revolución Mexicana, un

\footnotetext{
${ }^{1}$ Universidad de Granada, Granada. España.

E-mail: amarco@ugr.es
} 
ciclo cuya definición e inventario siguen resultando no obstante todavía polémicos. En un trabajo ya clásico, Antonio Castro Leal (1966: 18) adscribía al mismo el conjunto de narraciones "apasionadas y verídicas, palpitantes y autobiográficas", de extensión mayor que el simple cuento, aparecidas al fragor de la contienda inaugurada por la rebelión de Francisco I. Madero en noviembre de 1910, las cuales consignaban lo mismo la actuación dentro de esa realidad que la contemplación presencial de la misma. Sin embargo, se reconocen también a menudo bajo el perfil todas las creaciones que abordan la temática revolucionaria, incluyendo las de quienes sin haber participado en los hechos reflexionan sobre ellos desde la distancia y remiten a ellos para dar cuenta de la crisis sociopolítica de México en la segunda mitad del siglo XX. Son muchos en cualquier caso quienes prefieren calificar a estas últimas como "narrativa de la Posrevolución" (Lorente Medina 2008: 43) o asimilarlas a la "Nueva Novela Mexicana", conscientes de que la aparición en 1947 de Al filo del agua de Agustín Yáñez marca un punto de inflexión en el tratamiento de los acontecimientos históricos, que prescindirá cada vez más del enfoque documental, consolidará el legado de la vanguardia narrativa y acentuará la perspectiva crítica sobre el proceso y sus repercusiones.

Con anterioridad al desarrollo de este lábil corpus, el folclore musical mexicano había dado cuenta de los sucesos revolucionarios a través de un ciclo propio, reflejo de la misma necesidad testimonial y valorativa que en buena medida animará a los escritores. Toda una serie de temas conoce así una doble codificación, al tiempo que es posible percibir en la escritura una atracción recurrente por el patrimonio melódico, que pasa a sus páginas en formas diversas. Ofrecer una panorámica de las relaciones entre este cancionero y la novela de la Revolución Mexicana constituye el objetivo de este trabajo, para lo cual nos centraremos en las obras en prosa aparecidas en la primera mitad del siglo XX, adscritas por lo común al Regionalismo literario. Extenderemos no obstante de manera puntual nuestras reflexiones a algún testimonio de la literatura que acompañó a un episodio como el de las guerras cristeras, independiente de la Revolución pero inscrito en la dinámica histórica y cultural puesta en marcha por ella.

\section{El corrido y la novela de la Revolución: confluencias}

Movida en parte por su vocación costumbrista, la novela de la Revolución convoca en sus páginas tanto fragmentos de corridos como de canciones populares surgidas con motivo del enfrentamiento y testimonios del cancionero lírico de la época. No obstante, más allá de presencias intertextuales y pese a lo arriesgado de establecer generalizaciones cuando se maneja un corpus que suscita desencuentros a la hora de establecer tanto sus rasgos distintivos como su nómina, ${ }^{2}$ son varias las voces

\footnotetext{
${ }^{2}$ Las dificultades al respecto comienzan por la discutida condición literaria de escritos que en muchos casos se aproximan a la biografía, el testimonio, las memorias o la crónica. Afectan también al hecho de que el conjunto aparece en un dilatado arco temporal, a la diversa adscripción generacional de sus autores, a la circunstancia de que estos no se ven animados por una misma concepción artística o un mismo posicionamiento ideológico e incluso a las intenciones dispares con que son alumbradas las obras.
} 
que han subrayado los aires de familia que aproximan de manera particular a la narrativa de la Revolución compuesta en las décadas del veinte al cuarenta y al corrido mexicano. ${ }^{3}$

¿Cuáles son las características y el sentido de estas confluencias? Para analizarlas, conviene repasar siquiera brevemente qué se entiende por corrido mexicano. El corrido hunde sus raíces en la tradición del romance peninsular, el cual se manifiesta en México a partir del siglo XIX con unas características lo suficientemente definidas como para diferenciarlo de su antepasado ibérico, si bien el romance seguirá constituyendo la base que proporcione a los corridistas estructuras y motivos elementales con los que elaborar relatos inspirados en las vivencias de su entorno (Hernández 1992). Entre los asuntos de los que se ocupa dominan los temas del enfrentamiento militar, el crimen pasional, el conflicto familiar, los ajusticiamientos, la narración de desastres naturales o el recuento de faenas campesinas, normalmente con el trasfondo de una fuerte competitividad entre individuos portadores de sistemas de valores enfrentados. Proliferan los protagonistas heroicos y carismáticos que con su arrojo para enfrentar la adversidad promueven la identificación de las audiencias y determinan en buena medida la supervivencia de las composiciones. Estas suelen ensalzar valores como la nobleza, el coraje, el orgullo, la lealtad y la generosidad, del mismo modo que abundan los ejemplos negativos en los que la contravención individual de las normas comunitarias es castigada con un final aciago. Los relatos se enmarcan a su vez en una estructura fuertemente tipificada, cuyo diseño suele ir pautándose en la propia composición por medio de una serie de expresiones formularias que contribuyen a rellenar nudos básicos del hilo argumental y de su diseño pragmático.

Condicionado por su naturaleza literario-musical y por las características de su difusión, el corrido resulta en consecuencia notablemente dependiente de la respuesta del público para el que se ofrece, ya sea en una ejecución en presencia ante receptores socio-culturalmente próximos, ya por medio de la reproducción impresa o fonográfica. De ahí que intérpretes y compositores intenten garantizarse el éxito a partir del trabajo con códigos asentados entre sus audiencias, multiplicando así la probabilidad de obtener una favorable acogida y contribuyendo a crear un género en esencia conservador, lo mismo desde el punto de vista estilístico que desde el axiológico. No es ello obstáculo sin embargo para que sus mensajes se revelen a menudo apartados de la moral vigente entre los sectores hegemónicos, con respecto a los cuales las comunidades corridísticas suelen colocarse en posiciones de marginalidad.

El género ha dado muestras de un extraordinario vigor, el cual le ha permitido llegar hasta nuestros días como un representante vivo del patrimonio folclórico mexicano. Y ello pese a que especialistas como Vicente T. Mendoza

\footnotetext{
${ }^{3}$ Christopher Domínguez Michael, por ejemplo, califica los trabajos de Nellie Campobello, Rafael F. Muñoz, Gregorio López y Fuentes, Francisco L. Urquizo o Mauricio Magdaleno de "épica menor", "corridos narrativos" (49) y advierte cómo "la fortuna de novelistas y cuentistas menores -Frías, la Campobello, Ramón Rubín- es la de haber llevado a nuestra prosa los ecos y los corridos nunca antes registrados de la vida cotidiana en México entre la guerra y la paz" (1991: 63). Por su parte, Juan Carlos Ramírez-Pimienta (2004) llama la atención sobre las relaciones entre narrativa y corrido en los cuentos de Rojas González y en novelas como Rescoldo de Antonio Estrada Muñoz.
} 
diagnosticasen su decadencia a partir de 1930, cuando su estilística comenzaría a hacerse cada vez más artificiosa y su naturaleza más desvinculada de la épica. Sin embargo, desde ese momento no habrían dejado de sucederse recreaciones de comportamientos heroicos individuales -e incluso colectivos-, aparecidos al hilo de las reivindicaciones políticas y de la realidad social de la que se nutren cancioneros como el del migrante o el del narcotráfico.

Por otra parte, el énfasis excesivo en la naturaleza épica del corrido ha contribuido a soslayar las dimensiones líricas y novelescas que le son asimismo consustanciales (González 2003) y que explican que su vitalidad tras el intervalo revolucionario haya reposado en muchos casos también en el desarrollo de aspectos relativos al conflicto personal, una circunstancia en absoluto ajena a muestras decimonónicas de literatura popular como el romance de ciego o de cordel. De la vertiente "vulgar" del romancero, de gran éxito durante los siglos XVIII y XIX, así como de la copla, habría heredado de hecho el corrido muchos de sus rasgos, entre ellos los concernientes al machismo, la bravuconería y el orgullo de muchos de sus protagonistas, con base en el arquetipo del guapo y el valentón peninsulares, pero también la tendencia a la moralización explícita, la querencia por lo tremendista y lo espectacular, o la complacencia ocasional en un lenguaje afectado y retórico, en contraste con el estilo sintético más propio del romance tradicional. ${ }^{4}$

La dimensión épica es en cualquier caso uno de los aspectos que primeramente se aducen para establecer la proximidad entre el corrido y la novelística de la Revolución. Ambos comparten efectivamente atributos propios de la macroforma épica: hallan inspiración en el hecho histórico y aspiran a convertirse en crónica de unos sucesos de trascendencia social, describiendo una lucha que intenta mejorar el estado de cosas imperante y en la que despuntan acciones heroicas de individuos y grupos. Por otro lado, si la primera novela revolucionaria es elaborada por hombres implicados en los acontecimientos descritos, también en el corrido de la Revolución el relator suele ser un testigo directo o bien informado. Esto no impide que el baladista dote a sus crónicas de una notoria intencionalidad artística mediada por las convenciones de la tradición folclórica en la que se inscribe-, lo que separa al corrido, como sucede a su vez con la novela, de la condición de mero documento histórico.

Una y otra convierten asimismo a los estratos populares en protagonistas. La presencia de las clases bajas en la narrativa pre-revolucionaria había sido más bien parcial y tendenciosa, destinada por lo general a refrendar tesis de carácter determinista sobre la corrupción del "vulgo" o propiciadora de reflexiones paternalistas sobre los infortunios de estos colectivos, sin motivar el análisis de las condiciones que explicaban su prostración. La novela de la Revolución convierte

\footnotetext{
${ }^{4}$ A este respecto pueden consultarse los trabajos de Aurelio González "El corrido del siglo XIX: caracterización novelesca del héroe" (2000), "El caballo y la pistola: motivos en el corrido" (2001) y "El corrido, expresión popular y tradicional de la balada hispánica" (2011). Acerca de la conformación del género, de la mezcla de registros y poéticas que concita y de sus vías de transmisión, destacan además estudios como los de Magdalena Altamirano, quien incide en la importancia del romance de pliego y de la lírica popular moderna, más aun que del romance tradicional, en la génesis del corrido en "La configuración del corrido tradicional mexicano" (2009), o Guillermo E. Hernández "El corrido ayer y hoy" (1992) y "New Perspectives on the Corrido"(1995), entre una cada vez más nutrida bibliografía.
} 
en cambio a las clases bajas, sobre todo a las de extracción rural, en su núcleo temático y reconoce en ellas a sujetos capaces de hazañas de extraordinaria significación. Pese a todo, no dejan de sucederse tampoco aquí ni las generalizaciones de corte demagógico ni los distanciamientos conscientes de los autores con respecto al "pueblo". Si en Vasconcelos, Azuela o Guzmán esta circunstancia se halla en íntima conexión con su extracción burguesa y liberal, en casos como los de Muñoz o López y Fuentes la simplificación conviene entre otras razones a un proyecto literario que, en pos del rédito comercial y condicionado por los modos de la difusión periodística y por entregas, opta por los mensajes contundentes y por la primacía de la acción y la tensión dramática en detrimento del matiz psicológico.

Pero es igualmente cierto que en sus mejores encarnaciones la codificación arquetípica de lo popular confirió un poderoso aliento mítico a la novela revolucionaria. Tanto este hecho como su carácter frecuentemente testimonial y memorialista terminan por separar a un sector de la novela de la Revolución Mexicana de lo estrictamente novelesco, aproximándola en cambio al terreno de la narración y con ello al de la oralidad. Y es que, como recuerda Walter Benjamin (1973: 306), a la novela la distingue de la narración el hecho de estar esencialmente referida al libro: "No venir de la tradición oral (ni ir a ella) es lo que aparta a la novela de todas las otras formas restantes de literatura en prosa -fábulas, leyendas, incluso narraciones cortas-". Frente al discurso autónomo, diferido, atento a las distancias que separan al mundo real del de la idealidad, hostigado por el desencantamiento crítico weberiano propio de la novela (Zumthor 1989: 306), la narración, que arraiga su matriz en el universo de lo oral, requiere de figuras excepcionales, de paradigmas hacia los que volver los ojos en una búsqueda de ejemplaridad. Pauta mnemotécnica en primera instancia, la oralidad precisa de la hipérbole, de tipos y motivos capaces de destacarse de la grisura ambiente y que puedan por lo mismo ser fácilmente recordados.

Nos hallamos así ante una literatura que fluctúa entre dos polos, el de la novelística, en el sentido que había venido a rubricar el siglo XIX, y el de la narración, atravesada por lo épico y por lo mismo celebradora de un "súper-ego comunitario", tendente a la creación de tipos más que de personajes en el sentido moderno del término y henchida con una "carga mítica" (Domínguez Michael 1991: 30). Así lo advierte también Marta Portal (1980: 364) al señalar que cuando los autores de esta literatura buscan desmitificar el uso político de la Revolución lo que hacen es traer primero a escena "a la Revolución remitificada en su estallido popular".

Los ejemplos en este sentido son abundantes. Convirtiendo al bajo pueblo en sujeto central de su novela y presentándolo en sus momentos de grandeza como ejecutor de justicia social y redentor de causas concretas, Azuela sintoniza por ejemplo con la presentación de la lucha efectuada por buena parte de las baladas revolucionarias. Su distanciamiento del tipo de crónicas ofrecido por estas se hace sin embargo evidente en la segunda mitad de Los de abajo, donde describe comportamientos y actitudes que no se daban en las figuras históricas que inspiraron su relato y muestra a unos contingentes populares faltos de ideales y de 
autocontención, arrollados por la fuerza imparable de "la bola". ${ }^{5}$ Por su parte, el sistema de valores difundido por el grueso del corrido revolucionario muy pocas veces exalta la gratuidad de la violencia, que suele contemplarse como parte de un proceso de impartición de justicia y redistribución de la riqueza, o como defensa de una identidad amenazada, y a diferencia de Azuela, los corridistas evitan presentar como inherentemente populares desafueros como los cometidos por el batallón de Demetrio Macías en las páginas finales del libro. ${ }^{6}$

También Martín Luis Guzmán contribuye a delimitar una imagen de la mexicanidad y alimentar el mito literario del villismo a partir de códigos asentados en el folclore. En varias ocasiones a lo largo de El águila y la serpiente, Villa se presenta conforme a arquetipos que lo vinculan al "bandolerismo social", encarnado por individuos que, manteniéndose al margen de la ley, son capaces de desafiar con su osadía, su astucia y su carisma un sistema injusto. De esta manera, la novela se homologa parcialmente a un sector del ciclo corridístico dedicado al jefe de la División del Norte. En Guzmán se manifiesta de hecho de forma recurrente la atracción por la dimensión mítica del fenómeno revolucionario, por la Otredad que representan para el hombre de letras la primacía del instinto sobre la reflexividad y la defensa de la libertad personal aun a costa de la integridad propia, las cuales cree advertir en buena parte de los revolucionarios, así como el interés por apariencias, habilidades y expresiones vernáculas. De ahí que sazonen su relato afirmaciones como la siguiente:

A menudo me preguntaba yo en Ciudad Juárez qué hazañas serían las que pintaban más a fondo para la División del Norte: si las que se suponían estrictamente históricas o las que se calificaban de legendarias; si las que se contaban como algo visto dentro de la más escueta realidad, o las que traían ya tangibles, con el toque de la exaltación poética, las revelaciones esenciales. Y siempre eran las proezas de este segundo orden las que se me antojaban más verídicas (El águila y la serpiente, en Castro Leal 1966: 300).

No obstante, la seducción que sobre el escritor opera el ideal épico y revolucionario no deja nunca de verse contrarrestada por el cuestionamiento a que somete los excesos, la vesania y el oportunismo que advierte también como intrínsecamente populares.

Si bien lo predominante en el ciclo novelesco es entonces la alternancia entre ambas perspectivas, una tendente a la mitificación, más solidaria con la óptica popular y próxima a la ofrecida por el corrido, otra individualista, cuestionadora y crítica con esa misma realidad, conviene señalar que ciertos relatos, por diversas razones, hacen gala de una sobresaliente adhesión a la primera. Es el caso de textos en principio tan dispares como Cartucho (1931), de Nellie Campobello, en torno a

\footnotetext{
${ }^{5}$ Como recoge Stanley L. Robe (1979), el mismo Azuela declaró haber exagerado los rasgos de rudeza e impulsividad y la carencia de visión política del personaje de Demetrio Macías con respecto a las dos figuras que le sirvieron como modelo, Manuel Caloca y Julián Medina.

${ }^{6}$ Para una revisión de las contradicciones con que Azuela se posiciona en Los de abajo en relación a la racionalidad política popular y para otra aproximación a las vinculaciones del texto con el corrido pueden consultarse los trabajos de Max Parra "Villa y la subjetividad política popular: un acercamiento subalternista a Los de abajo de Mariano Azuela" (2002) y "Pancho Villa y el corrido de la revolución” (2007).
} 
las luchas entre las fuerzas de Venustiano Carranza y Pancho Villa en los estados de Chihuahua y Durango, o Rescoldo, de Antonio Estrada Muñoz, alegato en defensa del movimiento cristero duranguense aparecido en la tardía fecha de 1961 pero igualmente fiel a los modos realistas y documentales de la novela del treinta y el cuarenta.

El proyecto de reivindicar literariamente la revolución villista a partir de una recuperación de la memoria familiar y regional lleva a Nellie Campobello a reescribir historias que circulaban de viva voz y en forma de leyendas y canciones populares entre los habitantes del norte de México. De ahí que atraviesen su obra, particularmente desde la edición tenida por definitiva de 1940, un buen número de rasgos considerados por la etnolingüística como propios de los "géneros literarios orales". 7 Este hecho, junto a la naturaleza testimonial de un texto concebido a caballo entre la crónica y la ficción, otorgan a Cartucho una innegable proximidad a la poética corridística. Es más, la autora ensaya también la inserción en su obra de corridos y canciones, buscando aprovechar las implicaciones reivindicativas y emocionales del trabajo con manifestaciones asociadas a una ejecución en presencia, su contribución al enriquecimiento estilístico de la prosa y su capacidad para ofrecer una interpretación polifónica de acontecimientos que de este modo aparecen presentados no ya únicamente por boca del narrador, sino por una vocalización ajena y supuestamente solidaria con un sector de la memoria colectiva.

Una treintena de años después, Rescoldo, destacado exponente de la literatura cristera y una de las grandes novelas mexicanas de ambientación rural, repetirá pautas muy semejantes en un nuevo intento de aproximarse a una interpretación comunitaria y popular de la Historia, si bien en esta ocasión desde posiciones ideológicas antagónicas a las anteriores. Inspirado en la experiencia real de un grupo de alzados en las sierras de Durango, sus valores documentales y memorialistas lo aproximan en lo relativo a intencionalidad y afectación por el hecho histórico al corpus revolucionario y explican su opción por un modelo narrativo que participa de muchos de sus rasgos distintivos.

El escritor se ocupa de sucesos vividos durante su infancia, dando lugar a un alegato en defensa de la figura de su padre, Florencio Estrada, jefe militar muerto en combate en 1936. La obra se construye por ello en función de una parcialidad ideológica que, pese a no restarle méritos literarios, la ha hecho sin embargo objeto de un silenciamiento múltiple. Más allá de estas cuestiones, la prosa de Rescoldo se

${ }^{7}$ Las modificaciones de la edición de 1940 de Cartucho reflejan una mayor tendencia a lo épico, colectivo y legendario que la original, de corte más lírico y subjetivo. Estas son en parte consecuencia del trabajo de campo efectuado por la autora en el intervalo entre ambas ediciones, que la llevó a entrevistar a combatientes veteranos y a recopilar una importante serie de corridos y de leyendas regionales. La crítica señala por ello que, aunque sigue siendo la voz de Campobello niña la que cuenta, la mayoría de los añadidos se sustentan en historias que le han sido narradas por otros, intensificando así el registro regional de la memoria en torno a los hechos de armas (Tola de Habich 1999; Parra 1998, 2005). Parece ser que por influencia de Martín Luis Guzmán se procura además la eliminación de coloquialismos y una mayor sujeción del discurso al decoro y a una norma culta (Aguilar Mora 2000) y es posible que el influjo del escritor se halle también tras la decisión de mitigar el erotismo vinculado a la crudeza y precariedad de la guerra del texto original, modificaciones que lo alejan del tono primitivo más informal y conversacional (Glantz 2003: 33-36; Rodríguez 1998: 185). (Acometemos una revisión más detallada de las poéticas que confluyen en la obra y de sus relaciones con el cancionero en nuestro artículo "Presencia de pautas narrativas de la tradición oral y popular en Cartucho de Nellie Campobello", 2013.) 
revela muy próxima al discurso corridístico: el artificio por el que un narrador homodiegético cuenta su historia a un narratario también presente, ${ }^{8}$ convirtiendo prácticamente a la novela en la transcripción de un relato oral, y la habilidad de Estrada para fijar el habla dialectal de sus personajes, acercan los textos cantado y escrito y posibilitan además que canciones y corridos se imbriquen en la novela como parte de un continuum en el que, sin solución de continuidad, la voz ajena refrenda la verosimilitud de las escenas reconstruidas por la memoria del autor. La apelación al folclore resulta así otra vez consecuente, como sucedía con el relato de Campobello, con los propósitos políticos y reivindicativos de Estrada: representante de la tradición cultural local, este se dibuja como el correlato que en el terreno de lo patrimonial da cuenta de la legitimidad que rodea al movimiento cristero. De este modo, la identidad entre la visión de los hechos históricos propalada por el corrido y la consignada en el libro es máxima.

Como venimos observando, corrido y novela de la Revolución hallan también un entronque en lo relativo a su concepción formal. Generalizando, la novela de la Revolución Mexicana tiende a presentarse como un relato compuesto de cuadros y divisiones episódicas, que escoge sucesos fuertemente impresivos y que documenta una acción considerable. En esta poética del instante representativo, de la selección y la sequedad, se reconocen de modo muy perceptible las semejanzas entre las formas que consideramos.

En Cartucho se reiteran por ejemplo la frase corta y el ritmo ágil. Como muchos de los protagonistas de la balada, los personajes del libro quedan definidos a menudo por su acción en un instante crucial, convirtiéndose en paradigmas de conducta. Además, Campobello recurre con frecuencia al estilo formulario propio de la poesía narrativa oral, con múltiples reminiscencias de las fórmulas de apertura y cierre del corrido:

Salvador es de la calle Segunda del Rayo. Nació allí, fue de la gente de José Rodríguez (en Castro Leal 1966: 947).

Pablito Siáñez había nacido en Cerro Gordo, Durango. Cuentan los que lo trataron que fue un hombre muy valiente (961).

Lo mataron aquí, en Parral, allá por el mesón de El Águila (962).

Así rezan a su vez corridos como el de "Palomón":

En el año del catorce, tiempo de Revolución, en ese pueblo de Allende mataron a Palomón.

Fue soldado muy valiente de la gente de Elizondo, y lo iban a fusilar en el pueblo de Paso Hondo (en Hernández, The Mexican Revolution 1996: 97).

\footnotetext{
${ }^{8}$ Historia que no es otra que la de la muerte "anunciada" del coronel Florencio Estrada, referida nada más abrirse la narración, en otro entronque con la ordenación narrativa de las baladas en torno a muertes y ajusticiamientos, las cuales suelen comenzar presentando un desenlace trágico para desglosar luego las circunstancias que condujeron al mismo.
} 
Por otra parte, una novela como Tropa vieja (1943), del militar de profesión Francisco L. Urquizo, ofrece una precisa cartografía de los avances de una partida federal en el norte del país durante la primera parte de la guerra en la que los episodios bélicos de la toma de Torreón y Gómez Palacio son descritos con una parquedad enunciativa, una precisión y un dinamismo próximos a los de la balada. También la caracterización "repetitiva y enunciativa, de las calidades del héroe", que Carlos Fuentes (22) advierte en Los de abajo, sazona como un ingrediente esencial el ámbito grato a la reiteración del poema cantado.

La atracción por lo popular que generaron tanto el episodio revolucionario como, respondiendo a intereses diversos, el aparato institucional que fue consolidándose a su término, supuso además el ingreso a la literatura de un material lingüístico novedoso que habría de contribuir al desanquilosamiento de la prosa en español. Los asuntos narrados requerían la incursión de voces ignoradas o burladas por la literatura decimonónica, pero atendidas en el México posrevolucionario. Ajena en la mayor parte de los casos a una sintonía profunda con la dimensión verbal popular o a la elaboración estética de la misma, y detenida a menudo en el registro de una colección de rasgos sociolectales opuestos a los del propio narrador, la recreación novelística de formas del lenguaje popular y campesino fue con todo capaz de trascender en sus mejores ejemplos el pintoresquismo de las aproximaciones realistas y naturalistas precedentes. El discurso ganó merced a ello en ligereza, gracia y variedad estilística. El material folclórico se mostró como un apoyo decisivo en esta tarea, contribuyendo las innumerables interpolaciones de coplas y fragmentos de corridos a aproximar la escritura al universo de lo oral, pero proporcionando también, como en el caso ya mencionado de Cartucho, pautas discursivas y de representación.

Lejos sin embargo de proponer al corrido como fuente directa y exclusiva de una nueva concepción narrativa, es preciso recordar que la apelación al folclore se constituye solo como uno de los factores que incidieron en la opción de varios de estos escritores por la velocidad, la concisión y hasta un saludable desaliño estilístico. Muchos de los que cultivaron el tema de la Revolución se formaron en el trabajo en prensa y se vieron obligados a la entrega periódica de materiales, quedando condicionado por ello su estilo y traduciéndose este influjo en falta de pulimento, rapidez, abuso del cliché, esfuerzo por mantener el interés del lector a través del truco efectista, etc. Como folletín en El Paso del Norte aparece Los de abajo desde 1915, Vámonos con Pancho Villa (1931), de Rafael F. Muñoz, inicia su andadura como publicación por entregas en El Nacional y por su trabajo como redactor del diario vespertino El Gráfico se verá afectada la escritura de Gregorio López y Fuentes, quien tenía a su cargo en aquel una sección titulada significativamente "La novela de la vida real".

El caso de Rafael F. Muñoz es sin duda uno de los más representativos de las circunstancias que rodearon a la aparición de esta literatura, sobre todo en la década de los treinta. Simpatizante de Pancho Villa, exiliado por sus apoyos a Obregón frente a Carranza y más tarde protagonista de la vida editorial del país desde la dirección de El Nacional, su escritura se inserta de lleno en el contexto resultante de la consolidación del aparato gubernamental revolucionario y la actividad pedagógica promovida por el vasconcelismo. Como hace notar Max 
Parra (2005: 101), el aumento del público lector -un público que no obstante carecía de la formación suficiente para acceder a productos de la tradición "alta" o "culta"-, demandó una notable producción de literatura popular. La mayoría de esos nuevos lectores eran varones, con preferencia por los relatos de acción de corte realista, lo que explica en parte el porqué de la particular recuperación del tema revolucionario practicada por Muñoz, o el que su apelación a ciertos efectismos (violencia, pasiones desmedidas - por lo general, manifestaciones de lealtad, coraje, virilidad, etc.-) haya conocido una extraordinaria acogida.

El montaje de cuadros remite además en ocasiones a las técnicas cinematográficas con las que muchos escritores estaban familiarizados entre otros motivos por la atención que tempranamente suscitaron en la industria del cine los sucesos revolucionarios y los tipos humanos que los protagonizaron. Parte del aire innovador de esta novelística proviene así de su aprovechamiento de las cada vez más influyentes tecnologías de la imagen, el cine y la fotografía, y se relaciona incluso, como en el caso de Guzmán, con mecanismos puestos en marcha por la poesía vanguardista más vinculada al Futurismo. ${ }^{9}$

Resulta asimismo evidente que baladas y novelas de la Revolución comparten su temática y que por ello no podían sino coincidir en lo relativo a su imaginería. Por una parte, la inspiración documental de la narrativa de la Revolución, que abunda en la descripción de lugares, labores, hábitos y figuras característicos, es consecuente con su filiación costumbrista decimonónica. Por otra, esta presentación reiterada de tipos y costumbres forma parte de un complejo entramado cultural y político empeñado en la tarea de revestir de sentido al concepto de "mexicanidad", el cual afectará de una u otra forma al conjunto del arte mexicano de las décadas del veinte al cuarenta. Dicha tarea requería de la definición de los paradigmas que supuestamente conformaban "lo mexicano" y precisamente el universo de lo musical ofrecería una magnífica fuente de inspiración en este sentido. De hecho, las interpretaciones esencialistas del canto habían sido invocadas ya por la musicología mexicana de las primeras décadas del siglo XX, heredera de las teorías románticas, para la consignación de unas identidades cuya naturaleza dinámica y en permanente construcción tendía a ser negada:

Los cantos del norte [...] reflejan el carácter audaz de los fronterizos; las melodías lánguidas del Bajío [...] interpretan fielmente la melancolía de las provincias del centro; las canciones costeñas [...] nos descubren la voluptuosidad

\footnotetext{
${ }^{9}$ Las relaciones de la novela de la Revolución Mexicana con la fotografía han sido estudiadas recientemente por Max Parra en "Photography and the Literature of the Mexican Revolution" (2016). Es probablemente Cartucho, de Nellie Campobello, la obra del ciclo que más interés ha despertado en este sentido, con comentarios pioneros por parte de Gabriella de Beer (1979) y más adelante por autores como Jorge Fornet (1994), Kemy Oyarzún (1996), Irene Matthews (1997), Sophie Bidault (2003), Catalina Donoso (2007), Begoña Pulido (2011) o Daniel Avechuco Cabrera (2017), además del propio Parra. Cristopher Domínguez Michael ha subrayado asimismo la importancia de la fotografía en la técnica narrativa de Mariano Azuela, a la vez que destacado la influencia del cine en Campamento, de Gregorio López y Fuentes (1991: 48). También Aurelio de los Reyes había advertido que la escritura guzmaniana se apoyaba ocasionalmente "en los recursos estéticos del expresionismo [cinematográfico] alemán" (en Duffey 2006: 20). El cruce de influencias entre el cine y la narrativa de la Revolución son objeto de revisión detallada por Patrick Duffey en De la pantalla al texto (2006).
} 
de las tierras tropicales; los cantos, en fin, que hablan de amor, de vino y de tristeza, y que son populares en todo el país, encierran en su sencillez la vida entera del pueblo mexicano que ama, se embriaga y es triste (Revista Musical de México 1919, en Mayer-Serra 1941: 149).

Pues bien, la novela de la Revolución abundó en conceptualizaciones semejantes, estableciendo relaciones entre las melodías y los temas del cancionero y los rasgos supuestamente definitorios de la identidad del país: "Charlaban, indiferentes y distantes, los dorados. Uno de ellos, puesta la vista en el espacio sin límites, canturreaba: Ya te he dicho que al agua no bajes... El son melancólico -jalma mexicana!- subía al cielo y parecía quedarse prendido allá" (Guzmán en Castro Leal 1966: 400).

En este punto se plantea uno de los aspectos más problemáticos a la hora de poner en relación novelas y corridos. Ciertamente, los dos constituyen manifestaciones homologables solo en parte, a las que distancia entre otros elementos la diferente extracción de autores y compositores. Aunque en ambos casos nos hallamos ante panoramas autoriales heterogéneos, la base social de la que provino el grueso de la novelística de la Revolución, la de la pequeña burguesía provinciana, se mantiene apartada de los orígenes por lo general más humildes de los creadores de baladas. Los novelistas trabajaron además a lo largo de un dilatado arco temporal, frente a la copiosa cantidad de canciones y corridos gestados simultáneamente al fragor de los hechos de armas. De ahí que, por lo que respecta a la controvertida representación de lo "popular", muchas novelas de la Revolución codifiquen antes la ideología de la época de su escritura que la de aquella que retratan.

Es este un período especialmente complejo en este sentido puesto que, como señalábamos, durante el período de reconstrucción estatal que sucedió a los enfrentamientos tuvo lugar un enaltecimiento del componente "popular" y "revolucionario" de la sociedad mexicana en tanto que sustrato de la nacionalidad que constituía en realidad una estrategia de legitimación de la nueva clase dirigente supuestamente emanada de él. Hasta tal punto funcionó esta estrategia que el mito de la "personalidad del mexicano" terminó por convertirse en el pilar que desde el ámbito de la cultura contribuyó con más eficacia a la consolidación del nuevo régimen. Simplificando mucho, dicho mito promovía un sentimiento de orgullo patrio basado en una imagen monolítica de la identidad colectiva, capaz de subsumir las diferencias de clase y cultura y de minimizar las tentativas de oposición al aparato del Estado, el cual se identificaba convenientemente a su vez con "lo mexicano" (Parra 2005: 15).

La reflexión sistemática sobre el carácter nacional había partido no obstante ya de autores como Caso y Vasconcelos en su respuesta al pensamiento positivista del porfirismo y sería continuada por la denominada "filosofía de lo mexicano". A partir de la obra fundacional de Samuel Ramos El perfil del hombre y la cultura en México (1934) y de la mano de pensadores como Leopoldo Zea, Emilio Uranga o el propio Octavio Paz, esta da lugar asimismo a una imagen esencialista y mitologizante de la identidad nacional, la cual converge curiosamente en más de un punto con la propagada por la oficialidad de la que en principio estos intelectuales afirmaban disentir. 
Por una y otra vía, la del discurso nacionalista de Estado y la de la élite intelectual, y pese a sus distintos fines, se diseñan entonces definiciones reduccionistas que convierten al indígena melancólico y enigmático en estereotipo del mexicano tradicional, y al mestizo violento, festivo, borracho, machista y sentimental en imagen de la moderna base social del país. La mujer, por su parte, se perfila mayormente como un complemento del varón, anclada entre dos arquetipos dominantes, el de madre protectora y el de traidora y hembra fatal. Entre los argumentos aducidos para justificar estos delineamientos, se destaca la frecuencia con que estas caracterizaciones se reiteran en las manifestaciones culturales. Así lo hace por ejemplo Octavio Paz en su respuesta a las críticas vertidas al Laberinto de la soledad (1950) poco después de su aparición: "Muchos otros se han ocupado del mismo asunto: desde los cancioneros y autores de argumentos cinematográficos hasta los periodistas, los psiquiatras y los historiadores. No podía ser de otro modo: son obsesiones populares, cifras y claves de una sensibilidad" (2003: 59). ${ }^{10}$

¿Hasta qué punto es cierta esta afirmación? Las aseveraciones de Paz, como las de numerosos creadores, pensadores y miembros del establishment del momento, proceden a generalizar los rasgos con los que un sector del folclore, vinculado en buena medida a la literatura "vulgar" de pliego suelto $-\mathrm{y}$ ya en sus expresiones primigenias peninsulares-, describe a sus protagonistas, sin concederles por ello una dimensión ontológica colectiva. La cultura hegemónica posrevolucionaria alentará esta caracterización proponiéndola como emblema de la identidad nacional y seleccionando determinados atributos (machismo, agresividad, impulsividad, emotividad, religiosidad, orgullo, jactancia, problemas con el alcohol...) por encima de otros que se hallaban igualmente presentes en la tradición (lealtad, nobleza, generosidad, respeto, integridad, pericia en el desempeño de las labores propias...) pero que no resultaban útiles para presentar el atraso del país como una extensión del "ser mexicano" y no como un problema estructural o de mal gobierno. Pese a que la perspectiva patriarcal es la dominante en el corrido tradicional, Américo Paredes consigna por ejemplo que la palabra "macho" no hace su aparición en la balada hasta los años cuarenta del siglo XX (en Herrera-Sobek 1990: 111), mientras que la descripción del fin dramático de los personajes de corrido se corresponde con la intención de la literatura vulgar de pliego suelto de impresionar a sus receptores con grandes hechos trágicos y no presupone ningún desdén atávico del mexicano por la muerte (González 2000: 521). Con todo, esta tipificación será amplificada por los medios de comunicación masiva, que promoverán a su vez su interiorización en grandes sectores de la audiencia.

Muchas de las novelas adscritas al ciclo de la Revolución se hacen eco de este panorama y en su pintura de los sujetos populares se aproximan a las del corrido y la ranchera cinematográficos, los cuales no pasan sin embargo a esta literatura en tanto que materia intertextual. Los motivos de los escritores para recoger los estereotipos sobre "lo mexicano" son variados, respondiendo en ocasiones a un interés por generarse los favores institucionales, complacida la clase dirigente del

\footnotetext{
${ }^{10}$ Un análisis detallado de este proceso excede las posibilidades de este estudio. Pueden consultarse al respecto trabajos como los de Roger Bartra La jaula de la melancolía (1987), Jesús Martín Barbero De los medios a las mediaciones (1987) o Max Parra “El nacionalismo y el mito de 'lo mexicano' en Octavio Paz y José Revueltas" (1996).
} 
país con su representación. En otras, son traídos a primer plano con una intención crítica, en un proceso que, como sucedía con la "filosofía de lo mexicano", lo que hace entonces es aceptar de forma tácita estos atributos como constitutivos de la identidad nacional; o bien reflejan una voluntad de distanciamiento de los novelistas tanto de determinadas facciones en el poder, que responderían a esta caracterización, como del pueblo de donde habría surgido.

\section{La apropiación novelística del cancionero}

Más allá de confluencias estilísticas y temáticas, lo cierto es que la narrativa revolucionaria se ha servido conscientemente de la canción en numerosas ocasiones. Su presencia intertextual es en ella abundantísima y cumple funciones diversas, resultando la más evidente la que, en la línea típica del realismo y el regionalismo literarios, permite vivificar las descripciones costumbristas. Los autores aprovechan las posibilidades del verso intercalado tanto para caracterizar a personajes y grupos como para dar cuenta de manera impresionista de hábitos $\mathrm{y}$ tradiciones culturales: "Al son de las séptimas y las vihuelas o en el untuoso ritmo del órgano de boca cantan los corridos melancólicos y monótonos, las viejas canciones criollas, las tonadas sin inflexiones del otomí. La noche es la leyenda y la conseja, poblada del griterío de la gente de Marcial Cavazos, jinete redentor de caballito flamígero como San Jorge el del dragón" (Magdaleno, El resplandor, en Castro Leal 1966 vol. 2: 880).

El motivo musical atraviesa buena parte de los retratos que recrean la vida de las tropas, asiduas a la entonación de corridos y canciones sobre la lucha y la muerte: "Comieron con avidez, y cuando quedaron satisfechos, se tiraron de barriga al sol y cantaron canciones monótonas y tristes, lanzando gritos estridentes después de cada estrofa" (Azuela 2002: 83).

La presencia de la canción es notable en un texto como Tropa vieja (1943), de Francisco L. Urquizo, donde se mencionan los corridos de "Macario Romero", de "Tolentino" y de "Luis Banderas", amén de un gran número de coplas tradicionales. La música se presenta como desahogo del pobre ante una vida plagada de dificultades:

En la borrachera nos daba, como a todos los peones de La Laguna, por contar tragedias y canciones rancheras con sus correspondientes gritos y sus maldiciones. Ese es el consuelo de los hombres de trabajo cuando se sienten aliviados por un trago que les raspe el gañote.

Decía Macario Romero:

"Oiga, mi general Plata, concédame una licencia para ir a ver a mi chata" (en Castro Leal 1966: 372).

Son además muy frecuentes en el conjunto del ciclo las alusiones a fiestas y fandangos, la consignación de actuaciones de corridistas profesionales, la descripción de instrumentos o la incorporación de personajes músicos. El propio 
John Reed, periodista norteamericano autor de una conocida crónica sobre los acontecimientos de que fue testigo en México, llama la atención sobre las dotes parranderas de Madero y de Villa. A este respecto resulta célebre el pasaje en el que el corresponsal informa sobre las circunstancias de recreación colectiva y espontánea de corridos durante las campañas militares en el norte de México: "Uno de ellos comenzó a cantar esa extraordinaria balada, 'Las Mañanitas de Francisco Villa'. Cantó un verso, después otro cantó el siguiente, y así, en sucesión, cada uno de ellos iba componiendo un relato dramático de las hazañas del gran capitán" (Reed 1970: 75).

La novela de la Revolución ha sido invocada precisamente como un documento histórico de primera magnitud para conocer las circunstancias que rodearon a la interpretación tradicional de canciones y baladas. En La revancha (1930), de Agustín Vera, donde se suceden los intertextos de canciones de todo tipo revolucionarias, sentimentales, de apego al terruño...-, y en la que, como banda sonora de una panorámica del campo potosino, se escuchan los versos del "Desterrado me fui", se da cuenta de la costumbre de entonar canciones en los vivacs revolucionarios. No obstante, aquí la óptica de un novelista como Vera, para quien lo popular resulta todavía sinónimo de primitivismo y "otredad", se hace muy evidente: los versos son calificados de "incoherentes" y la monotonía de la música remite a nostalgias y pesares propios de "remotos antecesores" (en Castro Leal 1966, vol. 2: 826).

La relación entre el folclore y la vida de los alzados constituye un motivo fundamental de ese texto extemporáneo a la tradición que revisamos pero a la vez tan ligado a ella que es Rescoldo. Con la voluntad de registrar la cotidianidad de unos hombres embarcados en una vida nómada, marcada por la guerra y las privaciones, guarda relación la sostenida mención por Estrada de cantos y bailes y su descripción de duelos de interpretación e improvisación repentista. El escritor documenta también con precisión el ambiente y las circunstancias que acompañaron a la creación de los corridos surgidos al calor de los hechos de armas:

-¡Coronel Federico! -gritó uno de ellos-. Échennos para acá a su cantador. Sabemos que es un gallo para estos menesteres.

[...] Luego las tres guitarras comenzaron la música de unas mañanas que estrenaban:

-Señores, vengo yo de Durango, vengo a traerles una canción: es el corrido de los cristeros que allá hicieron la rebelión (Estrada Muñoz 1961: 129-31).

La música adquiere además para los huidos una condición especial, convertida tanto en sostén contra el desaliento como en una suerte de talismán, amén de en una vía de conexión con el mundo que han dejado atrás y por cuya supervivencia pelean.

Es a su vez intensa la cita de corridos que actúan como auténticos mise en abyme del conjunto del relato. No podían faltar por otra parte en un texto que supone la prosificación de esos mismos acontecimientos las referencias a un 
corrido como el de "La muerte de Florencio Estrada", obra de Ireneo Menchaca, alias "El Jabalín", célebre corridista del ejército de Estrada, que recupera la trayectoria del personaje hasta dar noticia de su muerte en el arroyo de Paso Ancho en 1936.

La novela registra al mismo tiempo una serie de estrofas líricas provenientes de coplas populares y de canciones sentimentales, puestas algunas de ellas en boca de las mujeres que acompañaban a los combatientes. Como en el caso de los corridos, estas desempeñan funciones estructurales y sirven eficazmente a la caracterización de los personajes. El mayor Estrada, cuyo acordeón constituye a su vez tanto un agente caracterizador de su temperamento como un leit-motiv recurrente en la organización de la narración, entona siempre al despedirse el último verso de "La Mancornadora", o alguno de "aquellas otras canciones que hablaban de hasta nunca". La primera mantiene además una relación directa con el núcleo argumental de la obra, pautado precisamente por las varias despedidas del héroe.

Un uso semejante del folclore realiza Nellie Campobello en Cartucho, donde se citan los corridos de Abelardo Prieto y de Martín López y se incorporan fragmentos de una canción popular de Chihuahua y de otra de la propia autora en torno a los jóvenes de la Segunda del Rayo, la calle de Hidalgo del Parral donde transcurren sus años de infancia y el núcleo espacial desde donde irradia la narración.

Pero son sin duda las canciones revolucionarias, las todavía hoy bien conocidas "Valentina", "Adelita" o "La Cucaracha", las que han merecido mayor interés por parte de los narradores del ciclo que revisamos. La primera es mencionada por López y Fuentes en Tierra (1932), por Muñoz en iVámonos con Pancho Villa! o por José Rubén Romero en Desbandada (1934). Sus versos han dado título también a obras muy diferentes, tanto desde el punto de vista genérico como temático o cronológico, de la colección de cuentos de Rafael F. Muñoz Si me han de matar mañana, aparecida en 1939, a la miscelánea publicada en 1986 por el periodista mexicano Pablo Espinosa Becerra o la compilación de relatos breves del venezolano Ígor Delgado Senior, de 1999, todas de igual denominación. En cuanto a "La Adelita", parte de sus versos son reproducidos por El águila y la serpiente, de Guzmán, o, a modo de epílogo, íntegra, por algunas ediciones de Los de abajo. En esta, además, cuando los hombres de Macías abandonan una población una población en la primera parte del relato, victoriosos y queridos todavía por las gentes, "La Adelita" proporciona la música de fondo para su partida. "La cucaracha", himno carrancista, reaparece periódicamente en las páginas de La revancha, donde también se cita a "La Adelita" y a "La Valentina". A las tres las evoca asimismo una novela de tema revolucionario tardía, inspirada en los sucesos históricos de la ocupación norteamericana de Veracruz como Frontera junto al mar (1953), de José Mancisidor. Vasconcelos, por su parte, dedica en el segundo volumen de los cuatro que componen su autobiografía, La tormenta (1936), un ilustrador exordio a la primera.

Al propósito legitimador o la finalidad retórica que subyacen en un buen número de casos a la transcripción literal de textos orales se incorpora en otros su aprovechamiento como elementos destacados en la estructuración del relato y la construcción de la intriga. Como sucedía en Cartucho o Rescoldo, un buen número 
de estrofas figuran en la novela de la Revolución Mexicana a la manera de imagen especular y sintética de los sucesos descritos. Una posibilidad que pasa tanto por la cita directa como por la mera alusión a los temas, pues es frecuente que los narradores confien en la competencia de sus lectores para restaurar íntegros argumentos, ritmos y motivos. En el primer caso es preciso considerar la cita de versos de un corrido de leva como el de "Juan Soldado" por Urquizo en Tropa vieja, novela que documenta el enganche forzado a la milicia de un peón denunciado por borracho y alborotador: "De edad de quince años / me agarran prisionero / y me hacen soldado / del Quince de Puebla" (en Castro Leal 1966, vol. 2: 417). Con idéntico motivo, Gregorio López y Fuentes plantea en Tierra una suerte de paráfrasis a "La Leva", corrido que como el anterior da cuenta de la situación de los peones obligados a incorporarse al ejército.

Fragmentos del "Corrido de Marcial Cavazos", villista y defensor de la rebelión delahuertista en el estado de Hidalgo, atraviesan el recuento de la historia de San Andrés de la Cal ofrecido por Mauricio Magdaleno en El resplandor (1937). La balada rememora la actuación guerrillera y el final trágico de un modelo regional de resistencia a la dominación.

Desde Pachuca a Ixmiquilpan,
Actopan y otras regiones,
hostilizaba al gobierno
al frente de sus dragones (Magdaleno en Castro Leal 1966, vol. 2: 88).

La figura de Cavazos prefigura en las páginas escritas la de aquel en quien la comunidad indígena ha depositado sus esperanzas para liderar el cambio, Saturnino Herrera, que se revelará no obstante como una duplicación negativa del héroe popular, participando con singular avidez de la explotación de sus propias gentes. Por todo ello, la derrota del héroe corridístico terminará por constituirse a su vez como una anticipación trágica de la suerte que aguarda al pueblo.

También el carácter anticipatorio de los versos de "La Valentina" es advertido por el narrador de La revancha, que los convoca para dar cuenta por adelantado del destino que espera a los batallones objeto de su atención: "De la columna ... llegó el canto de combate. Era como una entrega en la que se expresaba el sacrificio anticipado y la despreocupación ante la muerte que ninguno tenía: Si me han de matar mañana, / que me maten de una vez...” (en Castro Leal 1966: 574-75).

Pero probablemente la literatura "culta" echa mano al folclore en su forma más característica como un medio con el que garantizarse tanto la proximidad empática a "lo popular" como la posibilidad de consignar una cosmovisión distinta a la dominante, asociada con valores de espontaneidad, pureza, ingenuidad o fuerza. La novelística vinculada a la Revolución Mexicana se ha mostrado particularmente atenta a la capacidad del canto para promover momentos culminantes de participación comunal: "Del centro de la ciudad, adonde el grueso de las fuerzas había llegado, venía un marcial rumor de cornetas y tambores y de voces de los soldados y la multitud que cantaban, fraternizando, las canciones que ahora los unían. El canto encerraba no sabía qué, una mezcla de fuerza y fatalidad, que 
embriagaba sus sentidos" (Mancisidor, Frontera junto al mar, en Castro Leal 1966, vol. 2: 575).

$\mathrm{Su}$ invocación cumple en este sentido dos funciones simultáneas, en las que lo estético se imbrica con lo ético. Por un lado, los modelos de heroísmo sancionados por las comunidades populares a través de la incorporación a la tradición corridística de determinadas trayectorias humanas son reconocidos y registrados por la literatura escrita, la cual exhibe hacia ellos grados diversos de identificación o de distanciamiento. Pero además la novelística consigue en determinados momentos equiparar su funcionamiento semiótico al de los textos cantados, apelando a su eficacia pática, de la que se procura participar aprovechando el poder evocador de lo melódico.

\section{Conclusiones}

La novela de la Revolución Mexicana y el folclore musical del país, en particular la tradición baladística del corrido, ofrecen un aire de familia que se concreta en aspectos diversos. Manifestaciones parcialmente enancadas en lo literario, ambas intentan ofrecer una revisión de hechos históricos sentidos como relevantes en sus comunidades de circulación, pretensión que no debe ser asimilada no obstante con la búsqueda de objetividad. La perspectiva parcial y localista del corrido corre en paralelo en este sentido a la de cuentos y novelas, cuya arbitraria evaluación del episodio bélico es resultante tanto de las presiones mediáticas que conlleva la aparición por entregas como del afán reivindicativo y del posicionamiento de los autores con respecto a un aparato institucional que se arrogará la representatividad revolucionaria al tiempo que pondrá freno en la práctica a muchas de sus aspiraciones.

Es precisamente esta circunstancia la que auspicia desde mediados de los años veinte y a lo largo de la década de los treinta una visibilización de lo popular que constituye otra de las señas de identidad de relatos y corridos, en cierto sentido realizaciones particulares de un mismo arquetipo épico. La novela de la Revolución recuperará el viejo anhelo épico de constituirse en relato de la colectividad, conviviendo en ella al igual que en la balada la inspiración en la Historia con la tendencia mitificadora y la presentación de acontecimientos y figuras en tanto que piezas ejemplares, si bien la novelesca tenderá a constituirse como una épica atravesada en buena medida por el distanciamiento y la crítica.

Pese a que tanto esta ambigüedad analítica como los diferentes origen y repercusión de las muestras las convierten en realidades no del todo homologables, no hay duda tampoco de que ocasionalmente narrativa revolucionaria y balada popular participan de unas mismas constricciones formales: ágil tempo narrativo, predominio de enunciados de acción y de movimiento, tendencia a la sobriedad, elisión de procesos psicológicos, supresión de episodios que son restituidos por la competencia genérica del receptor...

De la atracción por un mismo campo da cuenta además el interés de los novelistas por el cancionero, evidente en la abundante intercalación en su prosa de muestras de folclore. La funcionalidad de estas citas es diversa, siendo aprovechadas tanto para la promoción de un "efecto de realidad" y una ilusión de 
mímesis de "lo popular" en el seno del relato, como para la consignación en la propia ficción de documentos de época y la puesta en marcha de toda una serie de artificios narrativos que se sirven del enriquecimiento polifónico del texto con fines diversos: ilustrar una anécdota, condensar el motivo central de la historia, caracterizar vivamente situaciones y personajes o modelizar el plano de la intriga. Se aprovecha también en definitiva el poder evocador de la música, que sobreimpone el fraseo melódico a la mera lectura, y su remisión a imaginerías arraigadas en la memoria colectiva, capaces de promover un tipo de comunicación más intensa que la ordinaria y de dar cuenta de paso de la existencia de estilos de vida y sistemas de valores alternativos.

\section{Referencias bibliográficas}

Aguilar Mora, Jorge, "El silencio de Nellie Campobello", Kipus. Revista Andina de Letras, n. 12, 2000-2001, pp. 55-78.

Altamirano, Magdalena, "La configuración del corrido tradicional mexicano: cruce de géneros", en Mercedes Zavala (ed.). Formas narrativas de la literatura de tradición oral de México: romance, corrido, décima, leyenda y cuento. San Luis Potosí: El Colegio de San Luis, 2009, pp. 53-64.

Arias, Ángel, "Interludios musicales en la novela de tema cristero", en Ángel Esteban, Álvaro Salvador y Gracia Morales (eds.). Literatura y música popular en Hispanoamérica. Actas del IV Congreso de la Asociación Española de Estudios Hispanoamericanos. Granada: AEELH/Universidad de Granada, 2002, pp. 189-197.

Avechuco Cabrera, Daniel, "La Revolución narrada desde los márgenes: representaciones anómicas de la violencia en Cartucho, de Nellie Campobello", Literatura Mexicana, vol. XXVIII, n. 1, 2017, pp. 69-98.

Avitia, Antonio. Antonio Estrada, una literatura en el ostracismo. Durango: Gobierno del Estado de Durango/SECyD, 1994.

-Corrido histórico mexicano: voy a cantarles la historia. 5 vols. México DF: Porrúa, 1997-1998.

Azuela, Mariano. Los de abajo. Madrid: Cátedra, 2002.

Bartra, Roger. La jaula de la melancolía. México DF: Grijalbo, 1987.

Beer, Gabriella de, "Nellie Campobello, escritora de la Revolución Mexicana", Cuadernos Americanos, n. 223, 1979, pp. 212-219.

Benjamin, Walter, “El narrador”, Revista de Occidente, n. 129, diciembre de 1973, pp. 301333.

Bidault de la Calle, Sophie. Nellie Campobello: una escritura salida del cuerpo. México DF: Instituto Nacional de Bellas Artes y Literatura, 2003.

Bruce-Novoa, Juan, "La novela de la Revolución Mexicana: la topología del final", Hispania, vol. 74, n. 1, marzo de 1991, pp. 36-44. Disponible en: http://www.cervantesvirtual.com/nd/ark:/59851/bmcr50b1

Castro Leal, Antonio (comp. y pról.). La novela de la Revolución Mexicana. 2 vols. México DF: Aguilar, 1966.

Domínguez Michael, Christopher (sel., intr. y notas). Antología de la narrativa mexicana del siglo XX. 2 vols. México DF: FCE, 1991.

Donoso, Catalina, "Retrato hablado: la austera visualidad de los relatos de Nellie Campobello", Revista de crítica literaria latinoamericana, XXXIII, 66, 2007, pp. 173186. 
Duffey, Patrick. De la pantalla al texto. La influencia del cine en la narrativa mexicana del siglo XX. México DF: UNAM, 1996.

Estrada Muñoz, Antonio. Rescoldo, los últimos cristeros. México DF: Jus, 1961.

Fornet, Jorge. Reescrituras de la memoria: novela femenina y revolución en México. La Habana: Letras Cubanas, 1994.

Fuentes, Carlos, "Prólogo" a Mariano Azuela, Los de abajo. México DF: FCE, 2007, pp. 931.

Glantz, Margo, "Vigencia de Nellie Campobello", Anales de Literatura Española, vol. 16, n. 6, 2003, pp. 5-38.

González, Aurelio, "El corrido del siglo XIX: caracterización novelesca del héroe", Anuario de Letras, vol. 38, 2000, pp. 503-522.

— "El caballo y la pistola: motivos en el corrido", Revista de literaturas populares, año 1, n. 1, enero-junio, 2001, pp. 94-114.

- "Elementos tradicionales en la caracterización de personajes en el corrido actual", en Héctor Pérez Martínez y Raúl Eduardo González (eds.). El folclor literario en México. Zamora (Michoacán): El Colegio de Michoacán/Universidad Autónoma de Aguascalientes, 2003, pp. 135-148.

— "El corrido: expresión popular y tradicional de la balada hispánica”, Olivar, vol. 12, n. 15, 2011, pp. 11-36. Disponible en: http://www.fuentesmemoria.fahce.unlp.edu.ar/art_revistas/pr.4720/pr.4720.pdf

Hernández, Guillermo, "El corrido ayer y hoy: nuevas notas para su estudio", en José Manuel Valenzuela Arce (comp.). Entre la magia y la historia. Tradiciones, mitos y leyendas de la frontera. Tijuana: El Colegio de la Frontera Norte, 1992, pp. 215-229.

- "New Perspectives on the Corrido", en James Porter (ed.). Ballads and Boundaries: Narrative Singing in an Intercultural Context. Los Angeles: UCLA, 1995, pp. 28-36.

-(ed.) The Mexican Revolution Corridos. El Cerrito, California: Arhoolie Folklyrics Records, 1996.

— "El corrido de la Martina o romance de la Blancaniña: una cadena narrativa milenaria en versiones orales, impresas y electrónicas”, en Luis Díaz Viana (coord.). Palabras para el pueblo. Volumen 1. Aproximación general a la Literatura de Cordel. Madrid: CSIC, 2000, pp. 227-244.

Herrera-Sobek, María. The Mexican Corrido: a Feminist Analysis. Bloomington: Indiana University Press, 1990.

Leal, Luis, "Notas sobre el cuento de la Revolución Mexicana", en Luis Leal y Edmundo Valadés. La Revolución y las letras. México DF: CONACULTA, 1990, pp. 91-117.

Lorente Medina, Antonio, "La novela de la Revolución Mexicana", en Trinidad Barrera (coord.). Historia de la literatura hispanoamericana. Tomo III. Madrid: Cátedra, 2008, pp. 43-56.

Marco González, Ana, "Presencia de pautas narrativas de la tradición oral y popular en Cartucho de Nellie Campobello", Revista de Dialectología y Tradiciones Populares, vol. LXVIII, n. 1, enero-junio 2013, pp. 167-189. Disponible en http://rdtp.revistas.csic.es/index.php/rdtp/issue/view/25 DOI 10.3989/rdtp.2013.01.008

Martín Barbero, Jesús. De los medios a las mediaciones: comunicación, cultura y hegemonía. Barcelona: Gustavo Gili, 1987.

Matthews, Irene. Nellie Campobello. La centaura del Norte. México DF: Cal y Arena, 1997.

Mayer-Serra, Otto. Panorama de la música mexicana. Desde la Independencia a la actualidad. México DF: El Colegio de México, 1941.

Mendoza, Vicente T. El corrido mexicano, México DF: FCE, 1976. 
-1997 El romance español y el corrido mexicano. Estudio comparativo. México DF: UNAM, 1997.

Monsiváis, Carlos, "De las relaciones literarias entre 'alta cultura' y 'cultura popular'”, Texto Crítico, n. 33, 1985, pp. 46-61.

- "Notas sobre la cultura mexicana en el siglo XX", en Daniel Cosío Villegas (ed.). Historia general de México. México DF: Centro de Estudios Históricos-El Colegio de México, 2000, pp. 959-1069.

Nicolopulos, James, "The Heroic Corrido: a Premature Obituary?", Aztlán: A Journal of Chicano Studies, vol. 22, n. 1-2, winter 1997, pp. 115-138.

Parra, Max, “El nacionalismo y el mito de 'lo mexicano' en Octavio Paz y José Revueltas”, Confluencia. Revista hispánica de cultura y literatura, vol. 12, n. 1, 1996, pp. 28-37.

- "Memoria y guerra en Cartucho de Nellie Campobello", Revista de crítica literaria latinoamericana, vol. 24, n. 47, 1.er semestre, 1998, pp. 167-186.

— "Villa y la subjetividad política popular: un acercamiento subalternista a Los de abajo de Mariano Azuela", Foro Hispánico, n. 22, 2002, pp. 11-26.

-Writing Pancho Villa's Revolution. Austin: University of Texas Press, 2005.

_- "Pancho Villa y el corrido de la revolución", Caravelle. Cahiers du monde hispanique et luso-bresilien, n. 88, 2007, pp. 139-149.

- "Photography and the Literature of the Mexican Revolution", en Roberto Cantú (ed.). Equestrian Rebels. Critical Perspectives on Mariano Azuela and the Novel of the Mexican Revolution. Newcastle upon Tyne: Cambridge Scholars Publishing, 2016, pp. 25-45.

Paz, Octavio. El laberinto de la soledad. Madrid: Cátedra, 2003.

Portal, Marta. Proceso narrativo de la Revolución Mexicana. Madrid: Espasa-Calpe, 1980.

Pulido Herráez, Begoña, "Cartucho, de Nellie Campobello: la percepción dislocada de la Revolución mexicana”, Latinoamérica, n. 52, 2011, pp. 31-51.

Ramírez-Pimienta, Juan Carlos, "Búsquenme en el internet: características del narcocorrido finisecular", Ciberletras. Revista de crítica literaria y de cultura, vol. 11, 2004. Disponible en http://www.lehman.cuny.edu/ciberletras/v11/ramirezpimienta.html

Reed, John. México insurgente. Barcelona: Ariel, 1970.

Robe, Stanley L. Azuela and the Mexican Underdogs. Berkeley-Los Angeles: University of California Press, 1979.

Rodríguez, Blanca. Nellie Campobello: eros y violencia. México DF: UNAM, 1998.

Tola de Habich, Fernando, "Prólogo" a Cartucho. México DF: Factoría Ediciones, 1999.

Vanden Berghe, Kristine. Homo ludens en la Revolución. Una lectura de Nellie Campobello. Madrid/Frankfurt/México DF: Iberoamericana/Vervuert/Bonilla Artigas Editores, 2013.

Zumthor, Paul. La letra y la voz. De la “literatura” medieval. Madrid: Cátedra, 1989. 